\title{
Alterações genéticas na doença de Alzheimer
}

Cintia Fridman
Sheila P. Gregório
Emmanuel Dias Neto

Élida P. Benquique Ojopi

\begin{abstract}
Resumo
Com o aumento da expectativa de vida, visto hoje em todo o planeta, um maior número de indivíduos alcança uma idade avançada em que a manifestação de doenças neurodegenerativas é mais freqüente. Entre essas, a doença de Alzheimer (DA) é a causa mais freqüente de demência. Os achados mais marcantes na DA, em cérebros de pacientes acometidos pela doença, são as placas senis, os emaranhados neurofibrilares e a extensa perda neuronal. No entanto, existe uma carência generalizada de marcadores biológicos preditivos ou com valor diagnóstico para a DA. Estudos de genética molecular permitiram identificar quatro genes consistentemente associados com o maior risco de desenvolvimento da doença: APP, apoE, PSEN1 e PSEN2. No entanto, inúmeros estudos apontam para papel importante de outros genes, fortalecendo a hipótese de uma doença poligênica e multifatorial. Neste sentido, novas abordagens de estudo têm um futuro promissor, podendo indicar uma vasta população de genes ou alterações moleculares que possam explicar o surgimento da doença, vindo a fornecer as bases para a compreensão da DA e também para o delineamento de novas e mais eficazes abordagens de tratamento ou prevenção da doença.
\end{abstract}

Palavras-chave : Doença de Alzheimer, APOE, PSEN1, PSEN2, APP

\begin{abstract}
With the increase of the life expectancy that is seen today in the entire planet, a larger number of individuals reaches an advanced age when the manifestation of neurodegenerative illnesses is more frequent. Among these, the Alzheimer's disease (AD) is the most common cause of dementia. The most substantial findings in the brains of patients suffering from $\mathrm{AD}$ are the senile plaques, the neurofibrillary tangles and an extensive neuronal loss. However, a general deficiency of predictive biological markers for $\mathrm{AD}$ impairs the correct diagnosis and the better understanding of the disease. Studies of molecular genetics allowed the identification of four genes that are consistently linked to AD: APP, apoE, PSEN1 and PSEN2. However, diverse studies demonstrate that other genes also play important roles in the development of $\mathrm{AD}$, strengthening the notion that it is a polygenic illness. Modern large-scale techniques can now be applied in the study of AD, permitting the study of a vast population of genes or molecular alterations that can explain the origin of the illness, offering the basis for the understanding of the pathogenesis of $\mathrm{AD}$ and enabling the delineation of new and more efficient approaches to treat and to prevent the sprouting of the disease.
\end{abstract}

Key Words : Alzheimer's disease, APOE, PSEN1, PSEN2, APP

Recebido: 17/11/2003 - Aceito: 26/11/2003

Laboratório de Neurociências (LIM-27), Instituto de Psiquiatria, Faculdade de Medicina, Universidade de São Paulo

Endereço para correspondência:

Cíntia Fridman. Instituto e Departamento de Psiquiatria, Faculdade de Medicina da Universidade de São Paulo (FMUSP). Rua Dr. Ovídio Pires de Campos, s/n, 3( andar (LIM27). CEP: 05403-010. São Paulo, SP - Brasil. Telefone: +55 (11) 30697267 , FAX: +55 (11) 3062 4851. E-mail: cintiafri@hotmail.com 


\section{A Doença de Alzheimer}

O dramático aumento da longevidade humana, visto ao longo do último século, fez com que um grande número de indivíduos viesse a atingir uma idade crítica para o desenvolvimento de doenças neurodegenerativas. Dentre essas, a doença de Alzheimer (DA) surgiu como a mais importante doença neurodegenerativa da atualidade, atingindo proporções que a colocam com grande importância em termos de saúde pública. Na Europa, a doença ocorre em $0,02 \%$ dos indivíduos com 30 a 39 anos de idade, sendo mais freqüente nas faixas etárias mais avançadas, chegando a atingir $10,8 \%$ da população com 80 a 90 anos (Burns et al., 2002).

Atualmente, existe em todo o mundo cerca de 17 a 25 milhões de pessoas com a DA, que já acomete de $8 \%$ a $15 \%$ da população com mais de 65 anos. Dados atuais indicam que uma em cada 10 pessoas maiores de 80 anos deverá ser portadora da DA. Este mesmo índice em maiores de 70 anos de idade é de 1:100, e 1:1000 em maiores de 60 anos (Federação Espanhola de Associações de Familiares de Enfermos de Alzheimer - AFAF). Nos países desenvolvidos, a DA já é a terceira causa de morte, perdendo apenas para as doenças cardiovasculares e para o câncer.

Na década de 1960, com o advento da microscopia eletrônica, foi possível descrever as duas principais lesões cerebrais encontradas nos pacientes com DA: (1) placas neuríticas (ou senis), que contêm depósitos extracelulares de proteína $\beta$-amilóide (APP) e (2) um emaranhado neurofibrilar localizado normalmente no citoplasma perinuclear e composto de proteínas Tau hiperfosforiladas. Essas lesões clássicas podem ocorrer de maneira independente e, até hoje, não há um consenso se as mesmas seriam causas ou conseqüências do desenvolvimento da DA.

Nas duas décadas seguintes, a neuroquímica e a genética deixaram claro que a DA é uma doença altamente heterogênea, envolvendo alterações diversas, o que poderia explicar a dificuldade de se encontrar um tratamento eficaz. Já é sabido há muitos anos que a DA tende a se agrupar em algumas famílias, apresentando uma herança do tipo autossômica dominante na maioria dos grupos familiares estudados. As estimativas de prevalência de DA familial variam muito, indo de $5 \%$ a $10 \%$ até $50 \%$ em diferentes estudos (revisto em Selkoe, 2001). Os estudos de DA familial deixam claro que existe um componente genético bastante importante para o aparecimento da doença, fazendo com que o estudo de genes candidatos permita uma compreensão maior da mesma, abrindo caminho para futuros estudos terapêuticos.

\section{A genética da DA}

O estabelecimento da DA deve-se ao acúmulo de eventos genéticos e ambientais. Cada um desses eventos contribui com pequenos efeitos que resultam, em conjunto, no estabelecimento da doença com diferentes graus de severidade. Sabemos hoje que mutações nos genes codificadores para a APP [Amyloid b (A4) precursor protein], apoE (apolipoprotein E), PSEN1 (presenilin 1) e PSEN2 (presenilin 2) são consistentemente associadas com o estabelecimento da DA. Esses genes localizam-se em diferentes cromossomos e pelo menos alguns deles devem participar de uma via neuropatogênica comum, que culmine com o desencadeamento da doença. Esses quatro genes são, até o dia de hoje, os mais importantes e mais consistentes marcadores para a DA. No entanto, as alterações nos mesmos não são suficientes nem necessárias para explicar todos os casos de DA.

\section{DA: Marcadores genéticos atuais}

\section{ApoE}

Uma das primeiras alterações moleculares associadas com o estabelecimento da DA foi o polimorfismo da apoE (19q13.2) na sua variante denominada E4 (Weisgraber et al., 1981). O envolvimento do alelo $\varepsilon 4$ com o desenvolvimento da DA em casos esporádicos e familiais, assim como o fator protetor do alelo $\varepsilon 2$, são achados sólidos repetidos em diversas populações, incluindo um recente estudo em amostra brasileira (Souza et al., 2003). O reconhecimento de que alelos polimórficos da apoE acarretam uma predisposição maior para o aparecimento da DA sugere que outros genes também possam atuar na patogênese da DA (Selkoe, 2001).

Enquanto as mutações em outros genes (tais como APP, PSEN1 e PSEN2) mostraram-se um tanto infreqüentes entre os indivíduos com DA, a associação entre o alelo $\varepsilon 4$ da apoE mostrou-se como principal fator de risco para desenvolvimento da doença (Strittmatter et al., 1993). Esse alelo está representado em excesso nos indivíduos com DA, quando com- 
parados com a população em geral. A herança de um ou dois desses alelos eleva até cinco vezes a probabilidade de desenvolvimento da doença (Selkoe, 2001). Porém, devemos lembrar que a variante $\varepsilon 4$ do gene apoE é um fator de risco e não uma causa determinante de DA. Existem indivíduos que possuem os dois alelos de apoE na forma $\varepsilon 4$ e não apresentam DA, e também indivíduos que apresentam apenas alelos $\varepsilon 2$ ou $\varepsilon 3$, mas encontram-se acometidos pela DA. A importância da apoE na DA é grande, e um dos artigos desta revista trata exclusivamente desse tema.

\section{APP}

Três genes foram identificados como responsáveis pela forma rara da DA de início precoce: o gene da APP, o gene da PSEN1 e o gene da PSEN2. Entretanto, mutações nesses genes são responsáveis apenas por $5 \%$ do total de casos de DA. Os 95\% restantes são, na maioria, casos esporádicos de início tardio, com etiologia complexa devido a interações entre componentes ambientais e genéticos.

A primeira correlação genética mais consistente identificada para a DA foi a ocorrência de uma mutação "missense" (uma substituição de nucleotídeo que resulta em troca de aminoácido) em APP (21q21.3) (Goate et al., 1991). Apesar dos estudos extensivos, essa mutação só foi confirmada em alguns poucos pacientes clinicamente diagnosticados.

$O$ processamento da proteína APP resulta em fragmentos de $\mathrm{A} \beta$ de 40 e 42 aminoácidos, respectivamente. O fragmento de 42 aminoácidos é neurotóxico, e seu acúmulo resulta na formação de fibras amilóides e posterior acúmulo, formando as placas senis. Estudos sugerem que a redução no nível ou atividade dos fragmentos de APP, juntamente com o acúmulo de $A \beta$, poderiam ter um papel crítico na associação da disfunção cognitiva associada à DA, particularmente em estágios precoces da doença. A partir desses dados, fica claro que fragmentos de APP, incluindo $A \beta$, podem exercer uma poderosa regulação em funções neuronais básicas, como excitabilidade celular, transmissão sináptica e long-term potentiation. Assim, esses fragmentos devem estar relacionados à regulação também de comportamentos como aprendizado e memória (Turner et al., 2003). O peptídeo fibrilar A $\beta$ é depositado extracelularmente em forma de placas na amígdala, hipocampo e neocórtex de indivíduos afetados pela DA. Fragmentos intracelulares de APP ligam-se a fatores de transcrição e são transportados para o núcleo, onde passam a influenciar a transcrição. A regula- ção da proteólise de APP é dependente da atividade de um complexo protéico multimérico, cujos principais componentes são as presenilinas, a nicastrina, a PEN-2 e APH-1 (Gassen e Annaert, 2003).

\section{PSEN1 e PSEN2}

Uma das abordagens para a identificação de genes envolvidos com a DA consiste na busca de regiões cromossômicas que sejam constantemente herdadas junto com a doença, o que faz com que essas regiões estejam "ligadas" à doença, carreando genes de efeito causal. Os chamados estudos de associação estabeleceram o envolvimento de algumas regiões genômicas, tais como uma região do braço longo do cromossomo 14 e, por clonagem posicional, um novo gene foi identificado, a PSEN1 - 14q24.3 (Schellenberg et al., 1992; Sherrington et al., 1995). Mutações na PSEN1 são responsáveis por $18 \%$ a 50\% dos casos de DA com início precoce (Rogaeva, 2002). Algum tempo depois, um gene homólogo, denominado PSEN2, foi identificado no cromossomo 1 (1q31-q42) e apresentou-se mutado em alguns casos de DA (revisto em Hardy, 1997). Esses achados foram de extrema importância na elucidação da patogênese de DA, uma vez que é postulado que as presenilinas regulam o processo de formação de APP pelo seu efeito de gamasecretase, uma das enzimas que cliva APP.

Devemos reconhecer que mutações em APP, PSEN1 e PSEN2 são responsáveis por apenas 30\% a 50\% dos casos de herança dominante e início precoce e por apenas $\sim 10 \%$ dos casos familiais. Essas mutações herdadas fazem apenas uma pequena contribuição para o risco de desenvolvimento da doença em geral (Holmes, 2002). A DA de início tardio soma mais de 95\% dos casos e, embora já tendo sido relatados na literatura mais de 30 possíveis marcadores genéticos, até o momento, apenas o alelo $\varepsilon 4$ do gene apoE (19q13.2) mostrou uma associação consistente com a DA em muitos estudos independentes (veja revisão em Laws et al., 2003).

\section{Outros genes envolvidos com a DA: S $100 \beta$ e cPLA2}

A proteína S100ß (21q22.3) é expressa no sistema nervoso central e periférico e parece estar relacionada com a manutenção neuronal, participando também no processo cognitivo cerebral e na síntese da proteína precursora de $\mathrm{A} \beta$. A resposta ao processo de injúria ou disfunção neuronal que ocorre na DA acarreta a ativação de astrócitos que, por sua vez, leva a um aumento excessivo de expressão de $\mathrm{S} 100 \beta$, o que é tóxico para a célula. É sabido que astrócitos ativados são componen- 
tes reconhecidos nas placas senis. Assim, essa associação entre a expressão aumentada de $S 100 \beta$, quando da ativação de astrócitos, e placas $\mathrm{A} \beta$ na DA, junto com o efeito neurotrófico da $S 100 \beta$, sugere que essa expressão abundante de $S 100 \beta$ possa ser um fator patogênico importante no desenvolvimento e evolução das placas neuríticas na DA (revisão em Mrak e Griffin, 2001).

Evidências experimentais sugerem que os efeitos do acúmulo de $A \beta$ podem incluir o excesso de produção de radicais livres e danos peroxidativos de proteínas, lipídeos e outras macromoléculas. Assim, esse acúmulo resultaria em perturbação na membrana plasmática por agregados hidrofóbicos que podem alterar as propriedades funcionais de uma variedade de moléculas da superfície celular. Estudos do efeito do acúmulo de $A \beta$ em cultura postulam que uma das principais conseqüências seja uma alteração homeostática, mais particularmente um excesso de entrada de cálcio nos neurônios, o que poderia contribuir para disfunção e morte neuronal (revisão em Selkoe, 2001). É sabido que a enzima fosfolipase A2 (PLA2) influencia decisivamente o processamento e a secreção da APP. Uma inibição da PLA2 reduz a secreção da APP da membrana, enquanto que uma ativação da PLA2 aumenta a liberação da APP no meio extracelular (Emmerling et al., 1993). Uma vez que o aumento da secreção da APP diminui a formação do peptídeo $\beta$-amilóide (Caporaso et al., 1992; Fukushima et al., 1993), pode-se supor que uma redução da PLA2 contribuía para um aumento da produção do peptídeo $\beta$-amilóide. Essa suposição é apoiada pelos achados de uma correlação entre a diminuição da PLA2 e um número maior de placas senis no cérebro dos pacientes com DA, e pela correlação entre a diminuição da PLA2 e a maior severidade clínica da DA, já que a redução da atividade da enzima foi correlacionada com um início precoce da doença e menor idade ao óbito (Gattaz et al., 1995, 1996).

Um outro episódio patogênico importante na DA é a iniciação e proliferação da resposta inflamatória cérebro-específica, onde ocorre a ativação da fosfolipase A2 citosólica (cPLA2) (1q25); assim, existe uma correlação entre a DA e a diminuição da atividade da PLA2. A cPLA2 é expressa na maioria dos tecidos adultos, sendo o nível de expressão do mRNA mais elevado em cérebro, pulmão, fígado, coração, pâncreas e placenta (Pickard, 1999). A cPLA2 é uma enzima-chave na cascata de liberação do ácido aracdônico (AA), o qual produz vários eicosanóides (prostaglandinas) (Stephenson et al., 1996), sendo um importante modulador da função sináptica cerebral. Assim, o AA é transformado pelas lipoxigenases (LOX) para a biossíntese de leucotrienos, lipoxinas e ácidos hidroperóxidos (HPETE), ou pela ciclooxigenase 1 constitutiva (COX-1) e COX-2 para gerar produtos prostanóides, que incluem as prostaglandinas, prostaciclinas e tromboxanos (revisão em Bazan et al., 2002). Estudos epidemiológicos e clínicos mostraram a existência da influência de drogas antiinflamatórias não-esteróides (NSAIDS) na evolução da DA, fortalecendo a noção de que as enzimas COX devem ter um importante papel nos mecanismos da DA (Lukiw et al., 2000; McGeer et al., 1996). Assim, o estudo da cPLA2 e de outras proteínas relacionadas à sua via metabólica e excitotoxidade são importantes para que se possa compreender melhor os múltiplos aspectos envolvidos no desenvolvimento da DA.

Os genes descritos acima, assim como alguns outros que se encontram potencialmente envolvidos com a DA, são apresentados na Tabela 1 que também relaciona a localização cromossômica e os principais trabalhos que relacionam estes genes à DA. Para diversos destes, as alterações em seus produtos gênicos têm sido relacionadas com aumento na produção e/ou deposição cerebral de peptídeos A $\beta$ (componentes das placas amilóides). Esses estudos têm dado enorme suporte para a hipótese de que o acúmulo de $\mathrm{A} \beta$ é um evento necessário e invariante no desenvolvimento de DA (revisão em Selkoe, 1997).

Tabela 1: Genes ou regiões genômicas possivelmente associadas com a esquizofrenia

\begin{tabular}{|c|c|c|}
\hline Gene & $\begin{array}{l}\text { Localização } \\
\text { Cromossômica }\end{array}$ & Referências \\
\hline Presenilin 2 (PSEN2) & $1 q 31-q 42$ & $\begin{array}{c}\text { Finckh, U et al., } 2000 \\
\text { Arango, D et al., } 2001 \\
\text { Lleo, A et al., } 2001\end{array}$ \\
\hline $\begin{array}{l}\text { Alpha-2-macroglobulin } \\
\text { (A2M) }\end{array}$ & $12 \mathrm{p} 13.3-12.3$ & $\begin{array}{c}\text { Ganter, U et al., } 1991 \\
\text { Blacker, D et al., } 1998 \\
\text { Liao, A et al., } 1998 \\
\text { Zappia, M et al., } 2002\end{array}$ \\
\hline Presenilin 1 (PSEN1) & $14 q 24.3$ & $\begin{array}{c}\text { De Jonghe, C et al., } 1999 \\
\text { Sugiyama, N et al., } 1999 \\
\text { Arango, D et al., } 2001 \\
\text { Matsubara-Tsutsui, M, } 2002\end{array}$ \\
\hline $\begin{array}{l}\text { Angiotensin I converting } \\
\text { enzyme (ACE) }\end{array}$ & $17 q 23$ & $\begin{array}{l}\text { Zubenko, GS et al., } 1985 \\
\text { Narain, Y et al., } 2000 \\
\text { Isbir, T et al., } 2001\end{array}$ \\
\hline Apolipoprotein E (apoE) & $19 q 13.2$ & $\begin{array}{c}\text { Kivipelto, M et al., } 2002 \\
\text { Cruz-Sanchez, FF et al., } 2000 \\
\text { Rogaeva, E, 2001 } \\
\text { Lambert, JC et al., } 2002\end{array}$ \\
\hline $\begin{array}{l}\text { Amyloid precursor } \\
\text { protein (APP) }\end{array}$ & $21 q 21.3$ & $\begin{array}{c}\text { Sinha, S., } 2002 \\
\text { Sambamurti, K et al., } 2002 \\
\text { Bertram e Tanzi, } 2001\end{array}$ \\
\hline $\begin{array}{l}\text { S100 calcium binding } \\
\text { protein, beta (S100B) }\end{array}$ & $21 q 22.3$ & $\begin{array}{l}\text { Mrak e Griffinbc, } 2001 \\
\text { Peskind ER et al., } 2001\end{array}$ \\
\hline $\begin{array}{l}\text { Cytosolic phospholipase } \\
\text { A2 (cPLA2, PLA2G4A) }\end{array}$ & $1 q 25$ & $\begin{array}{l}\text { Gattaz et al., 1995, } 1996 \\
\text { Ross et al., } 1998\end{array}$ \\
\hline
\end{tabular}




\section{Polimorfismos em genes humanos}

Os SNPs (Single Nucleotide Polymorphisms) são a forma mais freqüente de variação na seqüência de DNA encontrada no genoma humano (Tailon-Miller et al. 1999) e podem ser definidos como regiões pontuais do DNA, onde a base nucleotídica seja variável na população. Os SNPs vêm ganhando grande popularidade nos últimos anos como um importante marcador utilizado nas pesquisas de doenças genéticas complexas (Kwok e $\mathrm{Gu}, 1999$ ). De acordo com modelos teóricos, se forem estudados os genótipos de um grupo de indivíduos portadores de uma determinada doença e os genótipos de um grupo-controle, observaremos que certos genótipos estarão consistentemente associados com aqueles indivíduos afetados, indicando um possível gene candidato para a doença em questão (Kwok e Gu, 1999).

Como a maioria do genoma humano parece não ser codificador para proteínas, a pressão evolutiva nessas regiões é reduzida, resultando em maior possibilidade de variação de seqüência, sem prejuízo para o organismo. Como conseqüência, a maioria dos polimorfismos está localizada nessas regiões não codificantes e não estão ligados diretamente com as características fenotípicas mais importantes. Contudo, quando os polimorfismos estão localizados em regiões codificantes, a alteração de um nucleotídeo pode levar a uma variação de aminoácido. Em alguns casos, a alteração de um simples aminoácido pode modificar a proteína, tornando-a mais ou menos ativa, ou ainda abolir completamente a sua função biológica. Esta classe de SNPs que podem alterar a seqüência protéica, os SNPs não-sinônimos, é particularmente importante, sendo o foco de estudo de uma série de doenças.

A análise de SNPs pode ser realizada usando as técnicas de PCR (Polymerase Chain Reaction) seguida de hidridização com sondas alelo-específicas, sequenciamento de DNA (Figura 1), ou análise de polimorfismos de tamanho de fragmentos gerados pela digestão do DNA com enzimas de restrição específicas (RFLP - Restriction Fragment Length Polymorphism). Nessas abordagens, podemos caracterizar os indivíduos como homozigotos, para o alelo selvagem ou para $\mathrm{o}$ alelo alterado, ou como heterozigotos.

Diferenças genéticas entre indivíduos têm um papel determinante na suscetibilidade a doenças, assim como na variabilidade de resposta a diferentes drogas. $\mathrm{O}$ grande desafio hoje é descobrir essa variabilidade genética na população e, então, definir as variantes genéticas ou alelos que contribuem para uma importante característica clínica. Essa diversidade genética na forma de SNPs tem sido bastante usada em farmacogenética. Desse modo, estudos farmacogenéticos baseados em genes candidatos permitirão melhor desenvolvimento de drogas, melhor triagem clínica e direcionamento do tratamento baseado no genótipo do indivíduo (Ring e Kroetz, 2002; Roses, 2001, 2002). Alguns estudos mostram que certos SNPs em determinados genes podem ser responsáveis pela resposta positiva ou negativa de um paciente a uma droga. Dessa forma, a análise genética poderia predizer a resposta do indivíduo a um certo tratamento, e aqueles indivíduos não-respondedores seriam conduzidos a um tratamento alternativo, sem que tivessem de passar semanas com um tratamento ineficaz.

Inúmeros estudos têm mostrado associação entre diferentes genes e a DA, corroborando a hipótese de uma doença poligênica. Assim, torna-se cada vez mais importante a identificação dessas associações. O achado de SNPs associados à DA permitirá compreensão maior da doença e, eventualmente, poderá possibilitar a adoção de tratamentos mais eficazes com uma redução do custo do tratamento e um melhor acompanhamento dos pacientes.

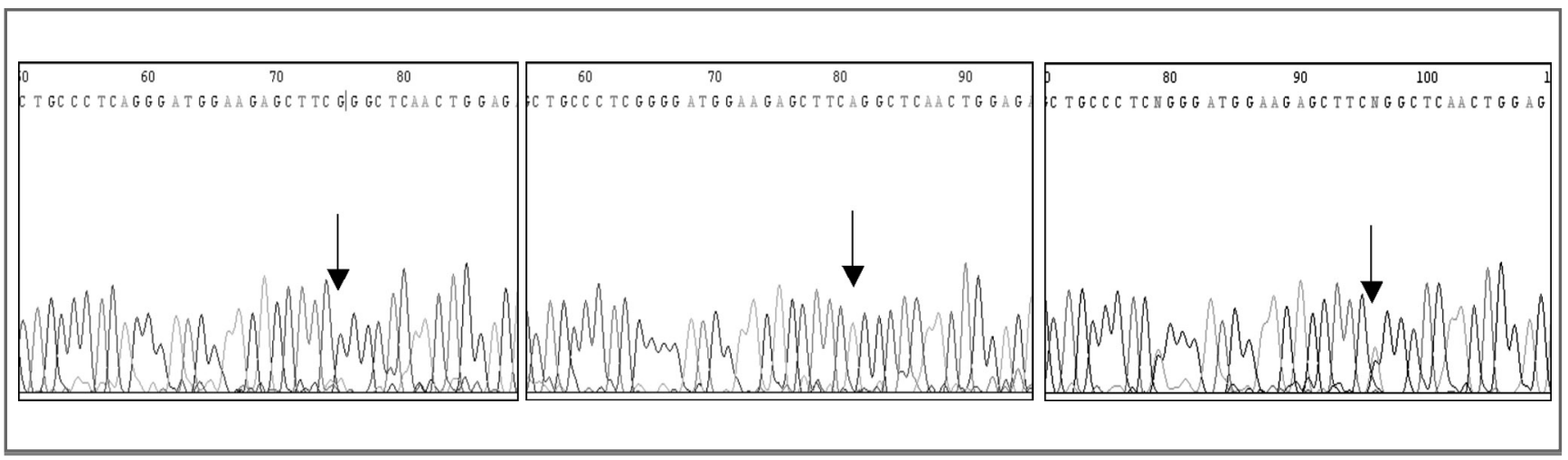

Figura 1 - Análise de SNP utilizando a técnica de sequenciamento. As setas indicam o local da ocorrência do polimorfismo. (A) homozigoto $G G,(B)$ homozigoto $A A,(C)$ heterozigoto $G A$ (notar a ocorrência de dois picos, verde e preto, indicando a presença das duas bases $G$ e $A$ ) 


\section{Perspectivas no estudo da DA}

Acredita-se que o estabelecimento da DA, como tantas outras doenças complexas, não ocorra devido a alterações em um único gene, mas seja resultante de um acúmulo de alterações, cada uma contribuindo com pequenos efeitos que resultam, em conjunto, no estabelecimento da doença com diferentes graus de severidade. Essas alterações podem ocorrer na forma de modificações em bases únicas e que levam à alteração na conformação e, algumas vezes, na atividade da proteína, tornando-a mais ou menos ativa ou então alterando a sua afinidade por um determinado sítio de ligação. Nesse caso, a análise de um grande número de polimorfismos (do tipo SNPs, microssatélites etc.) poderia ser de grande valia na busca de associações entre determinados genes e a DA.

Individualmente, esses genes podem ter pouca ou nenhuma influência e podem não estar envolvidos ativamente em todos os indivíduos que se enquadram nos critérios de diagnóstico para DA. No entanto, a identificação de um conjunto de genes consistentemente alterados nessa doença permitiria a eventual identificação de um conjunto mínimo de genes fundamentais para o desenvolvimento da DA.

A correta identificação de um grupo importante de genes que se manifesta antes do desenvolvimento da doença é enormemente dificultada pela indisponibilidade de material biológico adequado. Porém, a análise post mortem de cérebros de pacientes com DA tem levado a diversas teorias acerca das causas da patologia, sugerindo que esta doença envolva várias alterações fisiológicas. Uma das formas de se tentar entender a diversidade e a integração dessas alterações é a comparação do perfil de expressão gênica de regiões cerebrais afetadas e não afetadas e comparando-as entre casos e controles. Essa análise pode ser realizada através de técnicas de avaliação da expressão gênica em larga escala, como os microarrays de cDNA, ou a técnica de SAGE (Serial Analysis of Gene Expression).

A falta de marcadores moleculares, celulares ou anatômicos quantitativos/qualitativos dificulta o entendimento da neurobiologia da DA. A busca de SNPs ou de genes com padrão de expressão alterado poderia contribuir na elucidação da patogênese da DA, além de identificar genes de suscetibilidade específicos e alvos terapêuticos potenciais.

\section{Referências bibliográficas}

Arango, D.; Cruts, M.; Torres, O.; Backhovens, H.; Serrano, M.L.; Villareal, E.; Montanes, P.; Matallana, D.; Cano, C.; Van Broeckhoven, C.; Jaceuier, M. - Systematic genetic study of Alzheimer disease in Latin America: mutation frequencies of the amyloid beta precursor protein and presenilin genes in Colombia. Am J Med Genet 103: 138-43, 2001.

Bazan, N.G.; Colangelo, V.; Lukiw, W.J. - Prostaglandins and other lipid mediators in Alzheimer's disease. Prostaglandins Other Lipid Mediat 68-69: 197-210, 2002.

Bertram, L.; TANZI, R.E. - Of replications and refutations: the status of Alzheimer's disease genetic research. Curr Neurol Neurosci Rep 1 : 442-50, 2001.

Blacker, D.; Wilcox, M.A.; Laird, N.M.; Rodes, L.; Horvath, S.M.; Go, R.C.; Perry, R.; Watson, B. Jr.; Bassett, S.S.; McInnis, M.G.; Albert, M.S.; Hyman, B.T.; TANZI, R.E. - Alpha-2 macroglobulin is genetically associated with Alzheimer disease. Nat Genet 19: 357-60, 1998.

Burns, A.; Byrne, E.J.; Maurer, K. - Alzheimer disease. Lancet 360: 163 65, 2002.

Caporaso, G.L.; Gandy, S.E.; Buxbaum, J.D.; Ramabhadran, T.V.; Greengard, P. - Protein phosphorylation regulates secretion of Alzheimer $\beta A 4$ amyloid precursor protein. Proc Natl Acad Sci USA 89: 3055-9, 1992.

Cruz-Sanchez, F.F.; Durany, N.; Thome, J.; Riederer, P.; Zambon, D. - Correlation between Apolipoprotein-E Polymorphism and Alzheimer's Disease Pathology. J Alzheimers Dis 2: 223-9, 2000.

De Jonghe, C.; Cruts, M.; Rogaeva, E.A.; Tysoe, C.; Singleton, A.; Vanderstichele, H.; Meschino, W.; Dermaut, B.; Vanderhoeven, I.; Backhovens, H.; Vanmechelen, E.; Morris, C.M.; Hardy, J.; Rubinsztein, D.C.; St GeorgeHyslop, P.H.; VAN BroeckHoven, C. - Aberrant splicing in the presenilin1 intron 4 mutation causes presenile Alzheimer's disease by increased Abeta42 secretion. Hum Mol Genet 8: 1529-40, 1999.

Dermaut, B.; Theuns, J.; Sleegers, K.; Hasegawa, H.; Van den Broeck, M.; Vennekens, K.; Corsmit, E.; St George-Hyslop, P.; Cruts, M.; van Duijn, C.M.; VAN BRofCKHOVEn, C. - The gene encoding nicastrin, a major gamma-secretase component, modifies risk for familial early-onset Alzheimer disease in a Dutch population-based sample. Am J Hum Genet 70: 1568-74, 2002.

Emmerling, M.R.; Moore, C.J.; Doyle, P.D; Carroll, R.T; Davis, R.E. - Phospholipase A2 activation influences the processing and secretion of the amyloid precursor protein. Biochem Biophys Res Commun 197: 292-7, 1993

Finckh, U.; Alberici, A.; Antoniazzi, M.; Benussi, L.; Fedi, V.; Giannini, C.; Gal, A.; NITSCH, R.M.; BinetTI, G. - Variable expression of familial Alzheimer disease associated with presenilin 2 mutation M239I. Neurology 54: 2006-8, 2000.

Funushima, D.; Konishi, M.; Maruyama, K.; Miyamoto, T.; Ishiura, S.; Suzuki, K. - Activation of the secretory pathway leads to a decrease in the intracellular amyloidogenic fragments generated fom the amyloid protein precursor. Biochem Biophys Res Commun 194: 202 7, 1993.

Ganter, U.; Strauss, S.; Jonas, U; Weidemann, A.; Beyreuther, K.; Volk, B.; BERGER, M.; BAUER, J. - Alpha 2-macroglobulin synthesis in interleukin6-stimulated human neuronal (SH-SY5Y neuroblastoma) cells. Potential significance for the processing of Alzheimer beta-amyloid precursor protein. FEBS Lett 282: 127-31, 1991.

Gattaz, W.F.; Cairns, N. J.; Levy, R.; Förstl, H.; Braus, D.F.; Maras, A. - Decreased phospholipase A2 activity in the brain and in platelets of patients with Alzheimer's disease. Eur Arch Psychiatry Clin Neurosci 246: 129-31, 1996.

Gattaz, W.F.; Maras, A.; Cairns, N.J.; Levy, R.; Förstl, H. - Decreased phospholipase A2 activity in Alzheimer brains. Biol Psychiatry 37: 13-7, 1995.

Goate, A.; Chartier-Harlin, M.C.; Mullan, M.; Brown, J.; Crawford, F.; Fidani, L.; Guiffra, L.; Haynes, A.; Irving, N.; James, L.; Mant, R.; Newton, P.; Rooke, K.; RoQues, P.; Talbot, C.; PericaK-Vance, M.; Roses, A.; Williamson, R.; Rossor, M.; OWEN, M.; HARDY, J. - Segregation of a missense mutation in the amyloid precursor protein gene with familial Alzheimer's disease. Nature 349: 704-6, 1991.

Hardy, J. - The Alzheimer family of diseases: many etiologies, one pathogenesis? Proc Nat1 Acad Sci USA 94: 2095-7,1997.

HIRABAYASHI, T.; SHIMIZU, T. - Localization and regulation of cytosolic phospholipase A2. Biochim Biophys Acta 1488: 124-38, 2000. 
Holmes, C. - Genotype and phenotype in Alzheimer's disease. British Journal of Psychiatry 180: 131-4, 2002.

Isbir, T.; Agachan, B.; Yilmaz, H.; Aydin, M.; Kara, I.; Eker, D.; Eker, E. Interaction between apolipoprotein-E and angiotensin-converting enzyme genotype in Alzheimer's disease. Am J Alzheimers Dis Other Demen 16: 205-10, 2001.

Kehoe, P.G.; Katzov, H.; Feuk, L.; Bennet, A.M.; Johansson, B.; Wiman, B.; de Faire, U.; CAirns, N.J.; Wilcock, G.K.; BroOKeS, A.J.; BlenNow, K.; PrinCE, J.A. - Haplotypes extending across ACE are associated with Alzheimer's disease. Hum Mol Genet 12: 859-67, 2003.

Kivipelto, M.; Helkala, E.L.; Laakso, M.P.; Hanninen, T.; Hallikainen, M.; Alhainen, K.; Livonen, S.; MannermaA, A.; Tuomilehto, J.; Nissinen, A.; SoIninen, H. - Apolipoprotein E epsilon4 allele, elevated midlife total cholesterol level, and high midlife systolic blood pressure are independent risk factors for late-life Alzheimer disease. Ann Intern Med 137: 149-55, 2002

Kwor, P-Y.; Gu, Z. - Single nucleotide polymorphism libraries: why and how are we building them? Molecular Medicine Today 5: 538-43, 1999.

Lambert, J.C.; Araria-Goumidi, L.; Myllykangas, L.; Ellis, C.; Wang, J.C.; Bullido, M.J.; Harris, J.M.; Artiga, M.J.; Hernandez, D.; Kwon, J.M.; Frigard, B.; Petersen, R.C.; Cumming, A.M.; Pasouier, F.; Sastre, I.; Tienari, P.J.; Frank, A.; SulKava, R.; Morris, J.C.; St Clair, D.; Mann, D.M.; Wavrant-DeVrieze, F.; Ezquerra-Trabalon, M.; Amouyel, P.; Hardy, J.; Haltia, M.; Valdivieso, F.; Goate, A.M.; Perez-Tur, J.; Lendon, C.L.; Chartier-Harlin, M.C. - Contribution of APOE promoter polymorphisms to Alzheimer's disease risk. Neurology 59: 59-66, 2002.

Liao, A.; Nitsch, R.M.; Greenberg, S.M.; Finckh, U.; Blacker, D.; Albert, M.; Rebeck, G.W.; Gomez-Isla, T.; Clatworthy, A.; Binetti, G.; Hock, C.; Mufller-Thomsen, T; Mann, U; Zuchowski, K; Beisiegel, U; Staehelin, H.; Growdon, J.H.; TAnzi, R.E.; Hyman, B.T. - Genetic association of an alpha2-macroglobulin (Val10001le) polymorphism and Alzheimer's disease. Hum Mol Genet 7: 1953-6, 1998.

Laws, S.M.; Hone, E.; Gandy, S. et Al. - Expanding the association between the APOE gene and the risk of Alzheimer's disease: possible roles for APOE promoter polymorphisms and alterations in APOE transcription. J Neurochem 84: 1215-36, 2003.

Lio, D.; licastro, F.; Scola, L.; Chiappelli, M.; Grimaldi, L.M.; Crivello, A.; Colonna-Romano, G.; Candore, G.; Franceschi, C.; Caruso, C. Interleukin-10 promoter polymorphism in sporadic Alzheimer's disease. Genes Immun 4: 234-8, 2003

Lleo, A.; Blesa, R.; Gendre, J.; Castellvi, M.; Pastor, P.; Queralt, R.; Oliva, R. - A novel presenilin 2 gene mutation (D439A) in a patient with early-onset Alzheimer's disease. Neurology 57: 1926-8, 2001.

Mattson, M.P. - Excitotoxic and excitoprotective mechanism. Nuro Mol Med 3: 65-94, 2003.

Matsubara-Tsutsui, M • Yasuda, M: Yamagata, H • Nomura, T; Taguchi, K ; Kohara, K.; MiYoshi, K.; Miкı, T. - Molecular evidence of presenilin-1 mutation in familial early onset dementia. Am J Med Genet 114: 292-8, 2002

MrAK, R.E. GRIFFIN, W.S.T - The role of activated astrocytes and of the neurotrophic cytokine S100B in the pathogenesis of Alzheimer's disease. Neurobiol Aging 22: 915-22, 2001.

Narain, Y.; Yip, A.; Murphy, T.; Brayne, C.; Easton, D.; Evans, J.G.; Xuereb, J.; Cairns, N.; Esiri, M.M.; Furlong, R.A.; Rubinsztein, D.C. - The ACE gene and Alzheimer's disease susceptibility. J Med Genet 37: 695-7, 2000 .

Peskind, E.R.; Griffin, W.S.; Akama, K.T.; Raskind, M.A.; VAn Eldik, L.J. Cerebrospinal fluid $\mathrm{S} 100 \mathrm{~B}$ is elevated in the earlier stages of Alzheimer's disease. Neurochem Int 39: 409-13, 2001.

Pickard, R.T.; Strifler, B.A.; Kramer, R.M.; Sharp, J.D. - Molecular cloning of two new human paralogs of $85-\mathrm{kDa}$ cytosolic phospholipase A2. J Biol Chem 274: 8823-31, 1999.

Ring, H.Z.; Kroetz, D.L. - Candidate gene approach for pharmacogenetic studies. Pharmacogenomics 3: 47-56, 2002

Rogaeva, E.; Tandon, A.; St George-Hyslop, P.H. - Genetic markers in the diagnosis of Alzheimer's disease. J Alzheimers Dis 3: 293-304, 2001.
Rogatva, E. - The solved and unsolved mysteries of the genetics of early-onset Alzheimer's disease. NeuroMolec Medicine 2: 33-42, 2002.

Roses, A.D. - Pharmacogenetics. Hum Mol Genet 10: 2261-7, 2001.

Roses, A.D. - Genome-based pharmacogenetics and the pharmaceutical industry. Nat Rev Drug Discov 1: 541-9, 2002.

Ross, B.M.; Moszczynska, A.; ErLich, J.; KISH, S.J. - Phospholipid-metabolizing enzymes in Alzheimer's disease: increased lysophospholipid acyltransferase activity and decreased phospholipase A2 activity. J Neurochem 70: 786-793, 1998.

SAmbamurti, K.; Greig, N.H.; LAhiRi, D.K. - Advances in the cellular and molecular biology of the beta-amyloid protein in Alzheimer's disease. Neuromolecular Med 1: 1-31, 2002.

SchellenberG, G.D.; Bird, T.D.; Wijsman, E.M.; Orr, H.T.; Anderson, L.; Nemens, E.; White, J.A.; Bonnycastle, L.; Weber, J.L.; Alonso, M.E.; Potter, H.; Heston, L.H.; Martin, G.M. - Genetic linkage evidence for a familial Alzheimer's disease locus on chromosome 14. Science 258: 668$71,1992$.

Selkoe, D.J. - Alzheimer's disease: genotypes, phenotype and treatments. Science 275: 630-1, 1997.

Selkoe, D.J. - Alzheimer's disease: genes, proteins and therapy. Physiological Reviews 81: 741-66, 2001.

Sherrington, R.; Rogaev, Eim.; Liang, Y.; Rogaeva, E.A.; Levesoue, G.; IkedA, M.; ChI, H.; Lin, C.; Li, G.; Holman, K.; Tsuda, T.; Mar, L.; Foncin, J-F.; Bruni, A.C.; Montesi, M.P.; Sorbi, S.; Rainero, I.; Pinessi, L.; Nee, L.; Chumakov, I.; Pollen, D.A.; Roses, A.D.; Fraser, P.E.; Rommens, J.M.; St George-Hyslop, P.H. - Cloning of a novel gene bearing missense mutations in early onset familial Alzheimer disease. Nature 375 : 754-60, 1995.

SinHA, S. - The role of beta-amyloid in Alzheimer's disease. Med Clin North Am 86: 629-39, 2002.

SouZA, D.R.S.; De Godoy, M.R.; Hotta, J.; Tajara, E.H.; Brandão, A.C.; Pinheiro JR, S.; TognolA, W.A.; Dos SAnToS, J.E. - Association of apolipoprotein E polymorphism and late onset Alzheimer disease and vascular dementia in Brazilians. Braz J Med Biol Res 36: 919-23, 2003.

Stehenson, D.T.; Lemere, C.A.; Selkoe, D.J.; Clemens, J.A. - Cytosolic phospholipase A2 (cPLA2) immunoreactivity is elevated in Alzheimer's disease brain. Neurobiol Dis 3: 51-63, 1996.

Strittmatter, W.J.; Saunders, A.M.; Schmechel, D.; Pericak-Vance, M.; Enghild, J.; SAlvesen, G.S.; Roses, A.D. - Apolipoprotein E: high-avidity binding to $\beta$-amyloid and increased frequency of type 4 allele in late-onset familial Alzheimer disease. Proc Nat1 Acad Sci USA 90: 1977-81, 1993.

Sugiyama, N.; Suzuki, K.; Matsumura, T.; Kawanishi, C.; Onishi, H.; Yamada, Y; ISEKI, E.; KOSAKA, K. - A novel missense mutation (G209R) in exon 8 of the presenilin 1 gene in a Japanese family with presenile familial Alzheimer's disease. Mutation in brief no. 254. Online. Hum Mutat 14: 90, 1999.

Talllon-Miller, P.; Piernot, E.E.; Kwok, P-Y. - Efficient approach to unique single-nucleotide polymorphism discovery. Genome Research 9: 499-505, 1999.

Turner, PR.; O’Connor, K.; TAte, W.P.; Abraham, W.C. - Roles of amyloid precursor protein and its fragments in regulating neural activity, plasticity and memory. Prog Neurobiol. 70: 1-32, 2003.

Van Gassen, G.; Annaert, W. - Amyloid, presenilins, and Alzheimer's disease. Neuroscientist. 9(2):117-26, 2003

Weisgraber, K. H.; Rall, S. C., Jr.; Mahley, R. W. - Human E apoprotein heterogeneity: cysteine-arginine interchanges in the aminoacid sequence of the apo-E isoforms. J. Biol. Chem. 256: 9077-83, 1981.

Zappia, M.; Cittadella, R.; Manna, I.; Nicoletti, G.; Andreoli, V.; Bonavita, S.; Gambardella, A.; Quattrone, A. - Genetic association of alpha2-macroglobulin polymorphisms with $\mathrm{AD}$ in southern Italy. Neurology 59: 756-8, 2002.

Zubenko, G.S.; Volicer, L.; Direnfeld, L.K.; Freeman, M.; Langlais, P.J.; Nixon, R.A. - Cerebrospinal fluid levels of angiotensin-converting enzyme in Alzheimer's disease, Parkinson's disease and progressive supranuclear palsy. Brain Res 328: 215-21, 1985. 